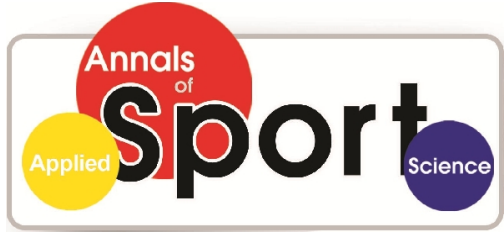

www.aasjournal.com

ISSN (Online): $2322-4479$

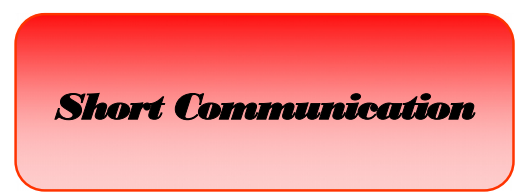

Received: $13 / 09 / 2013$

Accepted: 30/12/2013

\title{
Corneal Ectasis among Wrestlers: Report of Two Cases
}

\section{${ }^{1}$ Mohammad Ali Zare Mehrjardi, ${ }^{1,2}$ Hadi Zare Mehrjardi, ${ }^{3}$ Abasali Gaeeni, ${ }^{1}$ EIham Ashrafi, ${ }^{1}$ Homa Naderifar ${ }^{*}$}

1. Eye Research Center, Farabi Eye Hospital, Tehran University of Medical Sciences, Tehran, Iran.

2. Students' Scientific Research Center, Tehran University of Medical Sciences, Tehran, Iran.

3. Faculty of Physical Education and Sports Sciences, Tehran University, Tehran, Iran.

\begin{abstract}
Report keratoconus in two patients with a long history of wrestling without any risk factor for corneal ectasia and reviewing the possible pathogenesis. To confirm suspicion of keratoconus, corneal topography was performed using scanning slit topography system and Orbscan. In two wrestlers with the complaint of visual loss in their eyes and IOP raising, corneal topography was performed and development of keratoconus $(\mathrm{KCN})$ was detected. Athletes involved in sports with high strenuous exercises might need routine eye examination and also a baseline corneal topography. This may provide an earlier detection of $\mathrm{KCN}$ in this group of athletics.
\end{abstract}

Key Words: Wrestling, Cornealectasia, Intraocular Pressure, Keratoconus.

Corresponding Author:

Homa Naderifar

E-mail: hnaderifar@yahoo.com 


\section{INTRODUCTION}

Wrestling, a kind of martial art sport, is an Olympic game that is popular around the world. Although head or knee injuries are among the most common injuries in wrestling, ocular trauma also happens repeatedly. The sport is connected with repeated strenuous muscular efforts, forceful Valsalva maneuver, an inverted body position and repeated pushes to the eye. During all these conditions, significant intraocular pressure (IOP) elevation has been documented (1).

Cornea shape is affected by its elasticity, thickness and IOP (2). During normal conditions such as breathing and heart beating, IOP fluctuates within a fairly narrow diurnal range of about $5 \mathrm{mmHg}$ (3). However, activities involving Valsalva maneuver, strenuous muscular effort, inverted body position and eye rubbing can lead to large IOP elevations with an associated increment in the distending force loading on the cornea and sclera (4).

It has also been shown that small external forces like eyelid pressure during near work can cause transient changes in corneal shape (5).

It is believed that following IOP rise, structural changes occur in the cornea, especially in the presence of predisposing factors for corneal ectasia like enzymatic deficiency. Moreover, eye rubbing and pushes induce keratocyte apoptosis that may weaken the corneal stromal stability. Combination of this IOP elevation and induced wound healing changes secondary to eye rubbing trauma may contribute to the development of keratoconus (6). Keratoconus is a progressive, noninflammatory, ectatic disease of the cornea. The pathology is usually bilateral and can cause progressive corneal thinning and steepening ending in irregular astigmatism and scarring of the cornea (7).

As mentioned above, activities in wrestling are associated with significant IOP rise and repeated blunt eye trauma. Herein, we report two patients with corneal ectasia who had unremarkable history of associated risk factors but had been wrestling for a relatively long period.

\section{REPORT of the CASE}

Case 1. A 30-year-old man presented with the chief complaint of gradual and progressive visual loss in his both eyes. The patient was healthy and had no history of previous ocular pathology, surgery and/or trauma. His family history was also unremarkable for corneal ectasia or keratoconus. The patient had been wrestling for more than 14 years. The patient noted that his visual acuity had reduced bilaterally since years ago.

At baseline examinations, best spectaclecorrected visual acuity (BSCVA) was 10/10 in his right eye (with $+0.25-0.50 \times 450$ correction) and $9 / 10$ in the left eye (with Plano $-3.50 \times 130$ o correction). Slit-lamp examination was unremarkable for both eyes. In the left eye, scissor motion was observed during obtaining retinal red reflex. There was no evidence of papillary or follicular lesions on both tarsal conjunctivae. Posterior ocular segment examination was normal bilaterally. Intraocular pressure readings with Goldman applanation tonometry were within normal range at 12 $\mathrm{mmHg}$ for both eyes.

To confirm suspicion of keratoconus, corneal topography was performed using scanning slit topography system (Orbscan II Topography System, Bausch \& Laumb, USA). Provided maps showed an inferior steeping in the right eye and were completely compatible with keratoconus in the left eye (Figure 1). Results of anterior and posterior elevation maps were $20 \mu \mathrm{m}$ and $46 \mu \mathrm{m}$ in the right eye and $41 \mu \mathrm{m}$ and $99 \mu \mathrm{m}$ in the left eye, respectively. Corneal pachymetry maps showed thinnest points at 
$504 \mu \mathrm{m}$ and $474 \mu \mathrm{m}$ in the right and left eyes, respectively. Similarly, results of ultrasound pachymetry of central corneal thickness revealed corneal thinning in the left eye $(519 \mu \mathrm{m}$ right eye and $489 \mu \mathrm{m}$ left eye).

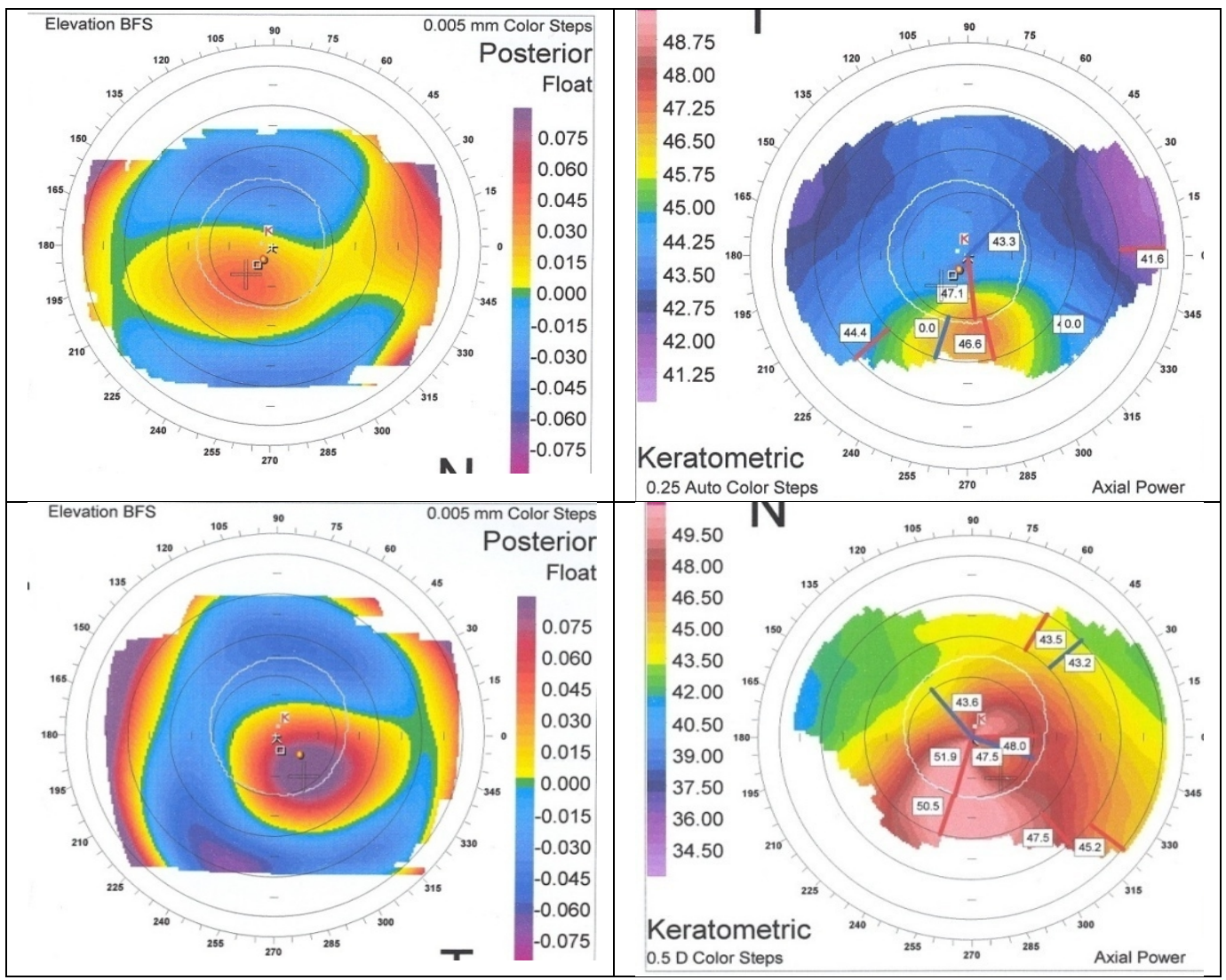

Figure 1. Inferior steeping in the right eye and were completely compatible with keratoconus in the left eye.

Case 2. A 35-year-old man presented (M.A.Z.) complaining of decreased vision in his both eyes. On questioning, he reported to have been wrestling for more than 20 years. His ocular and family history was unremarkable. He gave no history of vigorous habitual eye rubbing and was not diagnosed to have connective tissue disorder.

Slit-lamp examination of the anterior segment and fundoscopic examination of both eyes were normal. Intraocular pressure was $12 \mathrm{mmHg}$ in both eyes. Manifest refraction was Plano- $1.25 \times 150$ in the right eye and Plano-2.00 $\times 145$ oin the left eye. Irregularity in retinal light reflex was more noticeable in the left eye. Patient's BSCVA was 10/10 in his both eyes. Measurement of central corneal thickness was $489 \mu \mathrm{m}$ and $476 \mu \mathrm{m}$ in the right and left eye, respectively. External ocular examinations were normal.

Orbscankeratometric maps revealed a regular with-the-rule astigmatism in the right eye and typical inferior corneal steepening changes -suggestive of $\mathrm{KCN}$ - in the left eye (Figure 2). Anterior elevation map showed $11 \mu \mathrm{m}$ and $18 \mu \mathrm{m}$ elevation in the right and left eyes, respectively. Posterior elevation map showed $36 \mu \mathrm{m}$ and $52 \mu \mathrm{m}$ elevation in the right and left eyes, respectively. 


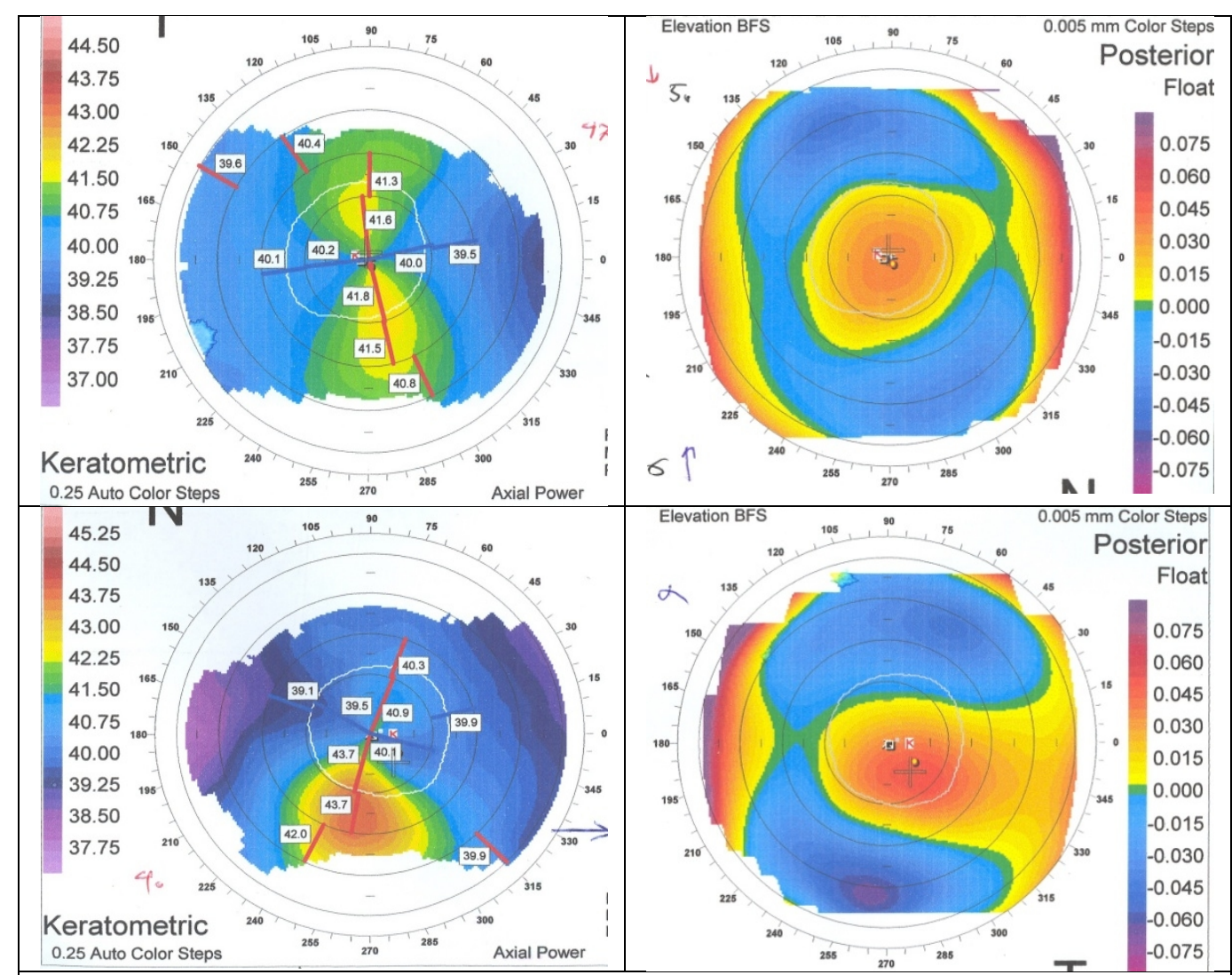

Figure 2. Regular with-the-rule astigmatism in the right eye and typical inferior corneal steepening changes -suggestive of $\mathrm{KCN}$ - in the left eye.

\section{DISCUSSION}

Although it is generally believed that keratoconus has a genetic component, there are increasing data suggesting that the environment might also play a role in the development of the condition.

In fact, cornea is not mechanically an inert tissue. It has been shown that any stimuli such as altered hydration, hypoxia and subsequent injury or surgery can manifest clinically as immediate corneal shape changes, shape instability over time and increased sensitivity to shape changes.

In wrestling sport, severe body injuries, especially on the head and neck, and repeated blunt eye trauma are not absolutely uncommon (8). Moreover, Valsalva maneuver, strenuous muscular efforts and inverted body position, which all are common events during wrestling, could induce significant IOP rise. It seems plausible to associate wrestling with occurrence of corneal ectasia in the possible mechanisms by which corneal ectasia associated with wrestling sport can be explained are repeated IOP-induced outward pushing of the cornea and release of interleukin by traumatized corneal epithelium which can follow the upregulation of matrix metalloproteinase, collagenases, and complement within stromal keratocytes and dead keratocyte (8). Keratocyte apoptosis, myofibroblast differentiation, and corneal wound healing may lead to corneal ectasia (9).

It has been found that corneas with keratoconus have been exposed to a number of factors that can produce reactive oxygen species (free radicals). These include 
ultraviolet light, atopy, mechanical eye rubbing, and poorly fitted contact lenses (8).

Both of our cases were male with a long history of wrestling. They did not have a history of any other ocular disease or a positive family history of $\mathrm{KCN}$. The only presenting complaint was decreased vision in both cases, and $\mathrm{KCN}$ was confirmed in both patients on ophthalmic examination, and also on corneal topographic maps.

\section{CONCLUSION}

Since there are no report on the association between the wrestling and $\mathrm{KCN}$, We recommend all athletics involved in sports with high strenuous exercises undergo a routine eye examination and also a baseline corneal topography. This may provide screening in order for the earlier detection of $\mathrm{KCN}$ in this group of athletics.

\section{REFFRENCES}

1. Chapman-Davies A, Lazarevic A. Valsalva maculopathy. Clinical \& experimental optometry : journal of the Australian Optometrical Association. 2002;85(1):42-5. Epub 2002/04/16.

2. Johnson CS, Mian SI, Moroi S, Epstein D, Izatt J, Afshari NA. Role of corneal elasticity in damping of intraocular pressure. Investigative ophthalmology \& visual science. 2007;48(6):2540-4. Epub 2007/05/26.

3. McMonnies CW. Keratectasia, rubbing, yoga, weightlifting, and intraocular pressure. Cornea. 2010;29(8):952; author reply -3. Epub 2010/05/29.

4. Liu WC, Lee SM, Graham AD, Lin MC. Effects of eye rubbing and breath holding on corneal biomechanical properties and intraocular pressure. Cornea. 2011;30(8):855-60. Epub 2011/04/21.

5. Buehren T, Collins MJ, Carney LEO. Corneal Aberrations and Reading. Optometry \& Vision Science. 2003;80(2):159-66.

6. McMonnies CW. Management of chronic habits of abnormal eye rubbing. Contact lens \& anterior eye : the journal of the British Contact Lens Association. 2008;31(2):95-102. Epub 2008/03/22.

7. Nomoto J, Seiki Y, Nemoto M, Takahashi H, Terashima H, Yokota K, et al. Head trauma in female professional wrestlers. Neurologia medico-chirurgica. 2007;47(4):147-51; discussion 51-2. Epub 2007/04/26.

8. Koenig SB. Bilateral recurrent self-induced keratoconus. Eye \& contact lens. 2008;34(6):343-4. Epub 2008/11/11

9. Korb DK, Greiner JV, Leahy CD, Hearn S. Forceful eye rubbing as a causative factor in keratoconus. Ophthalmol. 1996;100(Suppl):169. 


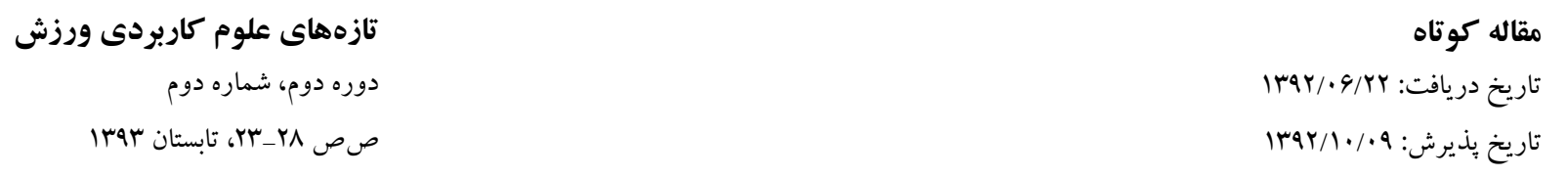

\title{
اكتازى قر نيه جُشهم در كثتى كيران: تَزارش دو مورد 'محمدعلى زارع مهرجردى، اوجهادى زارع مهرجردى، 'عباسعلى كايينى،

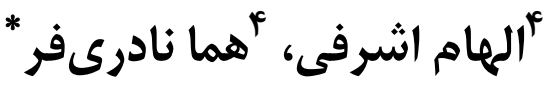

\begin{abstract}
ا. فوق تخصص قرنيه، مركز تحقيقات جشم بيمارستان فارابى، دانشگاه علوم يزشكى دانشخاه تهران، تهران، ايران.

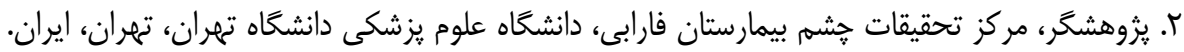

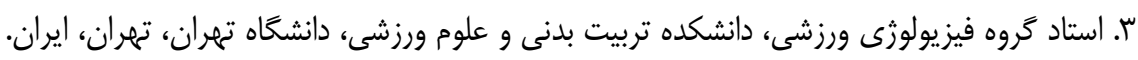

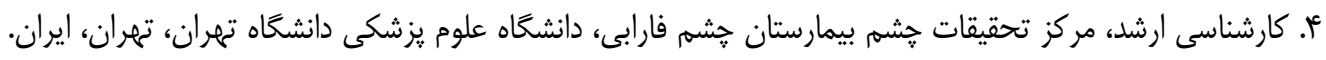

جكيده

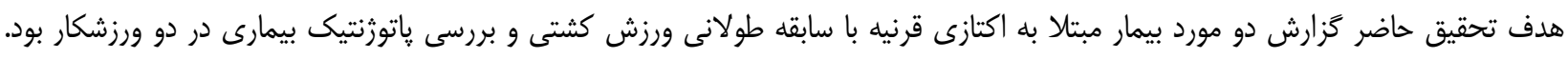

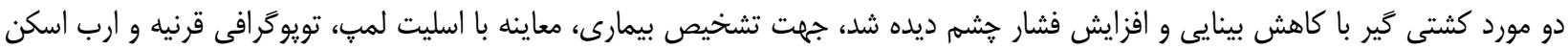

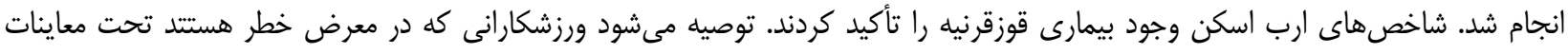

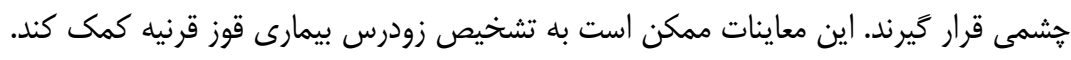

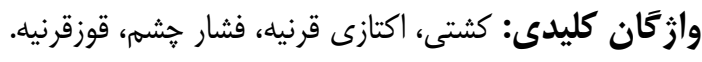

